\title{
INOVASI PENDIDIKAN: KONSEP DASAR, TUJUAN, PRINSIP-PRINSIP DAN IMPLIKASINYA TERHADAP PAI
}

\author{
J. Nabiel Aha Putra', Samsul Susilawati', Akbar A'thoni Elhaq ${ }^{3}$ \\ ${ }^{1}$ Universitas Islam Negeri Maulana Malik Ibrahim Malang \\ email:jaddnabiel@gmail.com \\ ${ }^{2}$ Universitas Islam Negeri Maulana Malik Ibrahim Malang \\ email: susilawati@pips.uin-malang.ac.id \\ ${ }^{3}$ Universitas Islam Negeri Maulana Malik Ibrahim Malang \\ email:loovus54@gmail.com
}

\begin{abstract}
Abstrak: Inovasi pendidikan di Indonesia, masih terfokus pada kurikulum yang berubah-ubah hal ini dipengaruhi oleh keadaan politik dan ekonomi. Sehingga, kerancuan penataan pendidikan akan selalu ada dan selalu terpicu. Kondisi pendidikan yang seperti itu, dapat memicu inovasi yang cukup banyak dan berkembang. Inovasi itu bahkan membuat pendidik akan sulit untuk, melaksanakannya kepada peserta didik. Maka, diperlukan sebuah ketegasan dan pembatasan dalam inovasi pendidikan. Sehingga, mampu memberikan dampak yang cukup baik bagi pendidikan. Penelitian ini bertujuan untuk menganalisis konsep, tujuan, prinsip dan implikasinya bagi pendidikan agama Islam. Hasil analisa menunjukkan bahwa, inovasi pendidikan harus mempunyai konsep dasar yang kuat. Sehingga tujuan dan prinsipnya akan berkesinambungan dan akan menghasilkan dampak yang baik, dengan menggunakan metode pembiasaan dari pada model konstektual hasil inovasi pendidikan itu. Tentunya akan mewujudkan peserta didik yang dapat mencapai tujuan dari pendidikan di Indonesia, yaitu menjaga amar makruf nahi mungkar dan al-Akhlaq al-Karimah. Implikasi ini, menjadikan pencapaian yang utama dalam pembelajaran pendidikan agama Islam.
\end{abstract}

Kata Kunci : Inovasi, pendidikan, Implikasi Terhadap PAI

\section{PENDAHULUAN}

I ndonesia mengalami kemerosotan. Adapun penyebabnya ialah Indonesia tak jarang menempatkan pendidikan pada urutan terakhir bidang yang harus diperbaiki padahal terkadang tanpa sadar bahwa pendidikan merupakan kunci utama dalam upaya membangkitkan Indonesia yang tengah terpuruk (Kadi \& Awwaliyah, 2017). Berbagai krisis telah mendera dan menerpa Indonesia semuanya berasal dari kerancuan yang disebabkan oleh elite sendiri mulai dari ekonomi, politik dan sosial kebudayaan. Ketiganya menjadi perebutan sentral dalam kerancuan di Indonesia. Terutama di bidang pendidikan kita telah tertinggal jauh dengan negara-negara lain di Asia bahkan dunia (Barizi, 2016). Maka haruslah Indonesia 
TAMADDUN : Jurnal Pendidikan dan Pemikiran Keagamaan

P-ISSN : 1693-3941; E-ISSN : 2722-2632

Vol. 22 No.1 Bulan Januari Tahun 2021

mengembangkan dan memajukan pendidikan di Indonesia dengan tidak meninggalkan sejarah yang perlu diambil dan dicontoh sebagai acuan kebangkitan dan kemajuan bangsa.

Pendidikan menjadi dasar utama manusia untuk meningkatkan kehidupan yang berpendidikan dan berkualitas sehingga berkualitaslah manusia dengan pendidikan yang telah dibudayakan dengan mengikuti segala aspek manusia yang ada bahkan hampir tidak ada manusia yang tidak melakukan sistem pendidikan pada dirinya (Hujair \& Sanaky, 2003). Penjelasan di atas mendefinisikan bahwa pendidikan adalah kunci dari segala aspek kehidupan yang menuju pengembangan kepribadian peserta didik. Lalu bagaimana jika pendidikan itu diarahkan pada pendidikan agama Islam tentunya bahwa pengembangan pendidikan keilmuan yang nantinya sebagai pendidikan oleh manusia diarahkan, ditujukan dan dimanifestasikan dengan melakukan ajaran-ajaran Islam dengan amar makruf nahi mungkar sehingga pengembaliannya juga kepada Allah SWT.

Pendidikan nasional berfungsi mengembangkan kemampuan dan membentuk watak serta peradaban bangsa yang bermartabat dalam rangka mencerdaskan kehidupan bangsa, bertujuan untuk berkembangnya potensi peserta didik agar menjadi manusia yang beriman dan bertakwa kepada Tuhan Yang Maha Esa, berakhlak mulia, sehat, berilmu, cakap, kreatif, mandiri, dan menjadi warga negara yang demokratis serta bertanggung jawab (SisDiknas, 2003). Dalam kaitannya dengan peraturan undang-undang maka dapat pula ditarik bahwa pendidikan di Indonesia haruslah mempunyai inovasi sehingga inovasi pembelajaran yang diarahkan pada pendidikan agama Islam tersebut akan mendapatkan hasil yang maksimal dan tidak akan kalah dengan negara-negara lain.

Inovasi pendidikan agama Islam menjadi sebuah dasar bagi keberlangsungan pendidikan yang tidak terus menerus monoton sehingga ketika pendidikan tersebut pada titik urgen maka inovasi pembelajaran ini perlu untuk diterapkan dengan sistematik. Era sekarang menjadikan pendidikan agama Islam harus terus bergerak dengan cepat efektif dan efisiensi dalam waktu dan kinerjanya sehingga pembelajaran pendidikan agama Islam tidak ketinggalan dengan keberlangsungan digitalisasi dunia yang semakin hari semakin maju dengan pesatnya.

Inovasi pendidikan yang sifatnya menjadi pembaharu atau udara segar sebagai cara untuk memberikan pendidikan yang terwujud secara dinamis dan reflektif bagi dunia pendidikan pada umumnya dan pendidikan agama Islam pada khususnya. Oleh karenanya lembaga pendidikan terutama pendidikan Islam harus terus mengevaluasi dan memberikan inovasi pendidikan yang sesuai dengan perkembangan zaman, kondisi yang terjadi dan diseimbangkan dengan apa yang dibutuhkan oleh peserta didik berkaitan dengan tingkatannya.

Inovasi seperti halnya sebuah kreativitas yang harus terus diubah untuk mencari formula yang sesuai dengan peserta didik. Kreativitas manusia berlaku pada hal penciptaan yang terus menerus yaitu mengubah suatu bentuk ke bentuk lain. Kreativitas ini meliputi semua aspek 
kehidupan manusia, seperti dalam ilmu pengetahuan, pemikiran, pendidikan dan lain-lain (Sutrisno, 2005).

\section{METODE}

Model Penelitian ini ialah bersifat kualitatif, yaitu menjelaskan dan menggambarkan keadaan sebenarnya. Dengan menggunakan metode studi literatur, yaitu dengan teknik mencari referensi dari sumber-sumber data yaitu buku-buku ilmiah yang berkaitan, jurnal yang berkaitan dan mungkin majalah ilmiah atau semacamnya (Syukwansyah \& Deden, 2016). Dengan metode penelitian ini, diharapkan akan menghasilkan hasil yang maksimal.

\section{HASIL DAN PEMBAHASAN}

\section{Konsep Dasar}

Konsep dasar inovasi pendidikan agama Islam menjadi sebuah dasar penting untuk mengupayakan pendidikan yang bermutu dan terjamin bagi setiap masyarakat yang sedang melakukan dan menjalankan pendidikan dengan sungguh-sungguh. Inovasi pendidikan yang arahnya untuk membentuk suatu ide pendidikan yang bersifat konstruktif sehingga dapat memunculkan ide tersebut ke dalam bentuk material sehingga dapat dituangkan kepada para pendidik dengan mengharapkan dapat menyelesaikan permasalahan pendidikan ataupun pembelajaran dalam tujuannya (Khairuddin, Wahyudin, \& Mardianto, 2018).

Dengan penjelasan tersebut penulis dapat memahami bahwa inovasi harusnya mampu untuk menjadikan sebuah proses dalam sebuah penyelesaian permasalahan pendidikan yang tidak sampai kepada objek pendidikan. Sehingga inovasi yang dibuat dan diciptakan haruslah inovasi yang dapat bertahan dan dapat dikembangkan pada kemudian hari. Menurut Ahmad Tafsir (Rusdiana, 2014) dalam bukunya inovasi pendidikan konsep dasar inovasi ada 3 hal, yaitu sebagai berikut: makna hakiki inovasi pendidikan, sasaran inovasi pendidikan dan bentukbentuk inovasi pendidikan.

Konsep dasar inovasi pendidikan tidaklah muncul begitu saja namun ada sebuah fenomenafenomena yang menjadikan inovasi pendidikan agama Islam harus diciptakan dan dikembangkan dengan sempurna walaupun prosesnya akan lama. Adapun fenomena menurut penulis yang mendasari terbentuknya konsep dan dasar inovasi pendidikan agama Islam sebagai berikut:

a. Masih Banyaknya para pendidik yang masih menggunakan metode yang bersifat tradisional. Hal ini dibuktikan dengan guru yang gagap menghadapi perubahan kondisi saat era pandemi seperti ini banyak guru yang ketinggalan bahkan kalah dengan siswanya.

b. Sebagian besar pendidik maupun peserta didik bahkan masyarakat beragama Islam di Indonesia saat menghadapi pandemi ini mereka dipaksa dan terpaksa harus mengikuti 
TAMADDUN : Jurnal Pendidikan dan Pemikiran Keagamaan

P-ISSN : 1693-3941; E-ISSN : 2722-2632

Vol. 22 No.1 Bulan Januari Tahun 2021

modernitas budaya yang hampir seluruhnya menggunakan digital yang terkoneksi dengan jaringan internet.

Berkaitan dengan fenomena-fenomena yang penulis sampaikan bahwa dengan hanya dibentuknya dan diciptakannya inovasi pembelajaran dan pendidikan agama Islam tanpa adanya dukungan dari steakholder maka ide dan gagasan yang telah dicanangkan ini tidak akan terwujud dengan sebagaimana yang di harapkan. Dengan ini maka pimpinan lembaga dan elemen yang berwenang harus memberikan dukungan yang bersifat positivistik sehingga elemen pendidik dan peserta didik akan dapat dengan tenang melakukan kegiatan tersebut.

Maka dengan ini penulis mencoba untuk menampilkan hambatan yang sering kali terjadi, sebagai berikut:

a. Setiap inovasi yang dicetuskan oleh seseorang maka menjadi inovasi yang baru, namun akan hilang dan sirna begitu saja jika tidak dirawat dengan baik.

b. Inovasi yang diinginkan dan yang akan diterapkan terkadang membutuhkan biaya yang besar sehingga pada elemen masyarakat akan kerepotan bahkan tidak mampu untuk mengikutinya.

c. Yang terkadang menjadi masalah terbesar sehingga menghambat inovasi pembelajaran ialah masih adanya elite kecil yang tidak setuju dengan perubahan yang dilakukan dan lebih memilih dan memegang yang sudah ada tanpa mengembangkannya lebih baik lagi.

d. Masyarakat Islam yang mempunyai dasar pembelajaran yang berasal dari kampung yang sehingga tidak cepat diintegrasikan dengan perkembangan zaman akan menjadi hambatan keilmuan untuk berkembang.

e. Berkembangnya populasi masyarakat Indonesia yang semakin hari semakin banyak sehingga banyak sekali siswa yang tidak tertampung oleh kesediaan fasilitas yang digunakan.

Pendidikan Nasional yang jelas dan terarah. Pameo umum menyatakan bahwasannya Indonesia tidak memiliki tujuan pendidikan yang jelas. Pada setiap pergantian pemerintahan secara otomatis akan terganti pula menteri serta kebijakannya. Hal tersebut disebabkan tidak adanya sesuatu yang mengikat Sistem Pendidikan Nasional dalam mencapai tujuannya. Masing-masing sektor dikenal memiliki egoisme sektoral yang sangat kuat sehingga berjalan sesuai keinginan masing-masing (Tilaar, 2004).

\section{Tujuan Inovasi}

Tujuan dari pendidikan Islam tentu ialah pendidikan pembelajaran yang bernuansa islami bahkan bukan hanya bernuansa namun juga ditempelkan keislaman pada dalam pendidikan tersebut. Pendidikan Islam haruslah mengimplementasikan dan merealisasikan pikiran-pikiran 
kuat tentang Islam yang di mana mempunyai makna bahwa pendidikan Islam itu berdasarkan iman dan ketakwaan umat Islam yang menjadikan Allah SWT sebagai awal dan dahulunya dari ilmu itu sendiri. Perjalanan pendidikan yang mempunyai tujuan mulia dengan berbagai inovasi pendidikan menjadi tugas oleh umat Islam sebagai khalifah untuk terus menambah keilmuan bagi diri mereka sendiri, sehingga mereka akan menyadari hakikat kehidupan dengan menggunakan wawasan yang mereka dapat sebagai pegangan untuk menganalisis dan membentuk inovasi pembelajaran yang baik.

Berkaitan dengan hakikat pendidikan pembelajaran jika dikaitkan dengan inovasi pendidikan dan pembelajaran pendidikan agama Islam tujuannya ialah menghapus dikotomi pendidikan. Negara yang ingin maju dalam perkembangannya maka harus memperhatikan pendidikan secara radikal (sedalam dalamnya) hingga tidak meninggalkan kesalahan sedikit pun tentu itulah yang didinginkan oleh negara. Jika negara hanya melihat dan merasakan saja itu tidaklah menjadi langkah yang baik, maka haruslah disatukan antara lembaga, akademisi, dan negara untuk turut mengeksekusi dan membuat inovasi yang baik dengan bersifat struktural dari atas hingga ke bawah sehingga dapat menghindarkan dari dikotomi yang selama ini menjadi permasalahan pendidikan (Naif, 2016).

Menurut Kusnadi secara sistematis tujuan inovasi pendidikan di Indonesia sebagai berikut (Kusnadi, 2017):

a. Dengan terus mengembangkan kemajuan sistem teknologi dan pengetahuan maka negara akan terus berupaya menggapai apa-apa yang akan menjadikan pendidikan di negara ini berjalan mengikuti dan seimbang dengan kemajuan zaman.

b. Terus berupaya berlaku adil dan terbuka untuk melayani serta memberikan wawasan yang baik kepada setiap elemen masyarakat

c. Mempertahankan dan juga memberikan sentuhan kembangan kepada pendidikan dan kebudayaan di Indonesia sehingga akan menjadikan lancar dan tanpa ada hambatan. Dengan memperkuat rasa nasionalisme, perkuat identitas dan terus menghidupkan pembelajaran yang intresting bagi peserta didik.

Tujuan utama dari inovasi ialah mengupayakan untuk terus menerus meningkatkan serta mengembangkan kemampuan dalam cakupannya secara finansial, ketenagaan, fasilitas dan sebagainya. Sehingga inovasi menjadi tujuan yang absolut bagi terwujudnya pendidikan sesuai dengan Undang-Undang 1945 Nomor 20 TAHUN 2003. TENTANG SISTEM PENDIDIKAN NASIONAL, Pasal 3. Tahap-demi tahap telah dilakukan untuk dijadikan sebagai acuan arah inovasi pendidikan.

Hal ini juga telah ditunjukkan oleh Allah SWT untuk terus berupaya mengubah diri ke dalam kebaikan dengan ini Allah bersabda dalam surah (Ar-ra'ad;11) yang berbunyi” sungguh Allah tidak mengubah keadaan sesuatu kaum sehingga mereka mengubah keadaan yang ada 
TAMADDUN : Jurnal Pendidikan dan Pemikiran Keagamaan

P-ISSN : 1693-3941; E-ISSN : 2722-2632

Vol. 22 No.1 Bulan Januari Tahun 2021

pada diri mereka sendiri”. Ayat ini telah memberikan pemahaman ke kita bahwa inovasi juga dapat diartikan sebagai proses perubahan menuju sebuah kebaikan dengan mengupayakan apa pun agar terwujud.

Berbagai model inovasi pendidikan telah banyak dilontarkan dalam berbagai bentuk, tujuannya untuk memecahkan persoalan-persoalan yang dihadapi, antara lain: usaha pemerataan pendidikan, peningkatan mutu, peningkatan efisiensi dan efektivitas pendidikan, dan relevansi pendidikan. Hal itu ditujukan agar inovasi yang dilakukan dapat diadopsi dan dimanfaatkan untuk perbaikan dan pemecahan problematika pendidikan di Indonesia (Senduk, 2003).

\section{Prinsip-prinsip Inovasi}

Inovasi mempunyai tujuan tertentu yang dihasilkan dari analisis, sistem, dan kerja keras. Kesemuanya dapat didiskusikan dan disajikan sebagai praktik inovasi. Dan justru itulah yang perlu ditampilkan karena jelas ia meliputi sekurang-kurangnya sembilan puluh persen dari semua inovasi yang efektif. Dan pelaku luar biasa dalam bidang inovasi seperti dalam setiap bidang lain hanya akan efektif bila didasarkan pada suatu disiplin dan penguasaan disiplin itu. (Anwar, 2018).

Terdapat prinsip-prinsip inovasi yang dimulai dari hal-hal kecil tersistematis dan efektif. Inovasi yang terarah dan sistematis akan menjadikan inovasi lebih tertata dengan baik dan tidak pula rancu dengan mempertimbangkan ide-ide inovasi, sistematis dan terarah telah menjadikan kurikulum Indonesia berubah ubah dalam waktu ke waktu sesuai kondisi dan perubahan yang ada. Lalu prinsip yang lain inovasi haruslah efektif, sederhana dan terfokus. Di mana inovasi ini diterapkan dengan betul-betul, Di dalam proses membangun suatu hal dibutuhkan rancangan awal dan sasaran yang tepat sehingga muncul keefektifan dalam berinovasi. Setelah itu menentukan alat yang akan digunakan dan mendukung proses inovasi. Konten dalam inovasi pendidikan pun harus spesifik sehingga inovasi sederhana dan terfokus. I

Sedangkan penulis mengidentifikasi adanya prinsip inovasi yang bermula dari hal-hal yang terkecil dikarenakan mulai dari hal-hal yang terkecil inilah maka pendidik akan lebih bisa dan dapat terus mengembangkan inovasi bagi peserta didik sehingga bermula dari hal kecil itulah maka akan menjadi sebuah ide atau gagasan dan implementasi yang baik pula.

\section{Implikasi Terhadap PAI}

Inovasi pendidikan agama Islam yang begitu banyak dan berkembang, membuat para pendidik sedikit kebingungan menentukan role model apa yang sesuai dengan apa yang akan mereka sampaikan. Oleh karenanya masih banyak sekolah dengan kurikulum yang ada, menggunakan metode pemaksaan layaknya pimpinan dengan bawahan. Hal ini masih saja di berlakukan di sekolah - sekolah yang cenderung lebih tertutup, atau bahkan yang berada di kota 
besar yang menuntut peserta didik harus semuanya pintar. Di lain hal ada dampak yang baik dan buruk yang akan terjadi.

Proses yang terus berjalan ini, memberikan sebuah perubahan alur pendidikan agama Islam yang terjadi saat ini. Dengan berubahnya pembelajaran yang berasal melalui hafalan terus di tingkatkan menuju pemahaman tujuan, lalu mencoba mengubah cara berpikir dari pemikiran yang kaku kepada pemikiran yang lebih modern atau bersifat empiris (Nurhadi, 2019). Akhirnya dengan kurikulum yang telah di sesuaikan, dengan kebutuhan akan memunculkan dampak yang signifikan.

Dampak yang didapat dari sebuah inovasi pendidikan, salah satunya munculnya model pembelajaran. Model pembelajaran yang dimaksud ialah pikiran-pikiran yang disusun secara terstruktur, yang berasal dari peristiwa-peristiwa nyata lalu di tulis dan dijadikan teori (Priatna, 2018). Pendidikan dengan berbagai model, yang nantinya akan dapat di integrasikan dalam pembelajaran pendidikan agama Islam.

Inovasi yang dimunculkan, melalui model pembelajaran salah satunya model pembelajaran konstektual. Pembelajaran ini menyinkronisasikan antara materi pembelajaran dengan keadaan yang sebenarnya (Ramdani, 2018). Dengan inovasi pendidikan, model ini sangat dibutuhkan oleh peserta didik. Peserta didik, akan lebih bisa memahami dan menghayati pembelajaran pendidikan agama Islam dengan keadaan nyata dan sebenarnya.

Model ini pun tidak dapat berdiri sendiri, namun juga di bantu oleh teknik atau metode yang sesuai dan cocok dengan model ini. Metode yang sesuai yaitu metode pembiasaan ialah teknik pembelajaran yang dilakukan dengan secara terus menerus ditujukan untuk mencapai apa yang akan dituju (Mukaromah, 2020). Pembiasaan yang dilakukan oleh pendidik, kepada peserta didik akan menghasilkan tujuan pendidikan dengan salah satunya akhlaq mahmudah.

\section{SIMPULAN}

Inovasi pendidikan memerlukan sebuah konsep, tujuan dan prinsip yang jelas. Sehingga, akan berimplikasi baik terhadap pembelajaran pendidikan agama Islam. Dalam konsep bahwa terbentuknya inovasi pendidikan, terdorong dari sebuah kondisi yang mengharuskan inovasi harus muncul. Namun tetap menjaga dan menguatkan, tujuan dan prinsip pendidikan. Jika hal ini terlaksana dengan baik dan benar maka, bentuk implikasi dari inovasi pendidikan terhadap pendidikan agama Islam melalui model pembelajaran konstektual dengan metode pembiasaan akan mampu melaksanakan amar makruf nahi mungkar dengan tujuan mencapai akhlaq mahmudah.

\section{REFERENSI}

Ahmad, Khairuddin Hidayah Harahap, Wahyuddin Nur Nasution, \& Mardianto. 2018. Inovasi Pembelajaran Pendidikan Agama Islam (PAI) di Sekolah Dasar Negeri 097523 Perumnas 
TAMADDUN : Jurnal Pendidikan dan Pemikiran Keagamaan

P-ISSN : 1693-3941; E-ISSN : 2722-2632

Vol. 22 No.1 Bulan Januari Tahun 2021

Batu VI Kecamatan Siantar Kabupaten Simalungun. EDU RILIGA, 2(2), (http://jurnal.uinsu.ac.id/index.php/eduriligia/article/view/1753)

Barizi, Ahmad. 2016. Menjadi Guru Unggul. Yogyakarta: Ar-Ruzz Media.

Hujair, AH dan Sanaky. 2003. Paradigma Pendidikan Islam Membangun Masyarakat Madani Indonesia. Yogyakarta: Safiria Insania Press.

HM, Muhammad Anwar. 2016. Inovasi Sistem Pendidikan. Jurnal Falasifa, VII(2). https://core.ac.uk/download/pdf/234747208.pdf

Kadi, Titi dan Robiatul Awwaliyah, 2017. Inovasi Pendidikan: Upaya Penyelesaian Problematika Pendidikan di Indonesia. Jurnal Islam Nusantara, (Online), 1(2), (https://jurnalnu.com/index.php/as/article/view/32)

Kusnandi. 2017. Model Inovasi Pendidikan Dengan Strategi Implementasi Konsep "Dare To Be Different”. Jurnal Wahana Pendidikan, 4(1), (https://jurnal.unigal.ac.id/index.php/ jwp/article/download/391/350)

Mukaromah, Ulin Nailatul. 2020. Metode Pembiasaan Kegiatan Keagamaan Intrakurikuler di MTs Negeri Model Pemalang. Journal of Educationalist, 1(2), (http://journal.muntahanoorinstitute.com/index.php/ije/article/view/7)

Naif. 2016. Urgensi Inovasi Pendidikan Islam: Menyatukan Dikotomi Pendidikan. KORDINAT, 15(1), (http://journal.uinjkt.ac.id/index.php/kordinat/article/view/6304)

Nurhadi. 2019. Analisis Kritis Konsep Kurikulum Pendidikan Islam Indonesia Di Sekolah (Sd, Smp, Sma, Smk). El Bidayah, 1(1), (https://ejournal.iai-tribakti.ac.id/index.php/ pgmi/article/view/671)

Priatna, Tedi. (2018). Inovasi Pembelajaran PAI di Sekolah Pada Era Disruptive Innovation. JURNAL TATSQIF, 16(1). https://journal.uinmataram.ac.id/index.php/tatsqif/article/ view/158

Ramdani, Emi. (2018). Model Pembelajaran Kontekstual Berbasis Kearifan Lokal Sebagai Penguatan Pendidikan Karakter. Jurnal Pendidikan Ilmu-Ilmu Sosial, 10 (1). https://jurnal.unimed.ac.id/2012/index.php/jupiis/article/view/8264

Rusdiana. 2014. Konsep Inovasi Pendidikan. Bandung: Pustaka Setia.

Senduk, N. 2013. Pembelajaran Kontekstual dan Penerapannya dalam KBK. Malang: Universitas Negeri Malang.

Sutrisno. 2005. Revolusi Pendidikan di Indonesia (membedah metode dan teknik pendidikan berbasis kompetensi).Yogyakarta:Ar-Ruzz.

Syukwansyah, Deden. (2016). Pengembangan Bisnis Joeragan Dengan Menggunakan Pendekatan Prinsip Efektual. PERFORMA: Jurnal Manajemen dan Start-Up Bisnis. 1(2). https://journal.uc.ac.id/index.php/performa/article/view/137 
TAMADDUN : Jurnal Pendidikan dan Pemikiran Keagamaan

P-ISSN : 1693-3941; E-ISSN : 2722-2632

Vol. 22 No.1 Bulan Januari Tahun 2021

Tilaar, H. 2004. Multikulturalisme (Tantangan-tantangan global masa depan dalam transformasi pendidikan nasional). Jakarta: PT Grasindo.

Undang-Undang 1945 Nomor 20 Tahun 2003. Tentang Sistem Pendidikan Nasional, Pasal 3. 